\title{
Büro Çalışanlarında Kuru Göz Sendromu ve Yaşam Kalitesi: Eskişehir Osmangazi Üniversitesi Örneği
}

\author{
The Dry Eye Syndrome and Quality of Life Among Office Workers in \\ Eskişehir Osmangazi University Hospital
}

\author{
Emrah Atay, Gökçe Dağtekin, Sevil Akbulut Zencirci, Hatice Aygar, Alaettin Ünsal, \\ Didem Arslantaş
}

Eskişehir Osmangazi Üniversitesi Tıp Fakültesi Halk Sağlığı Anabilim Dalı, Eskişehir, Türkiye

\begin{abstract}
Özet: Çalışmada, Eskişehir Osmangazi Üniversitesi Tıp Fakültesi hastanesi ve Dekanlığında görev yapan büro çalışanlarında Kuru Göz Sendromu (KGS) sıklığının saptanması, ilişkili olduğu düşünülen bazı faktörlerin incelenmesi ve yaşam kalitesinin değerlendirilmesi amaçlandı. Bu çalışma, Ocak-Nisan 2017 yılında Eskişehir Osmangazi Üniversitesi Tıp Fakültesi Dekanlığı ve Sağlık, Uygulama ve Araştırma Hastanesi'nde görev yapan büro çalışanları arasında gerçekleștirilen kesitsel tipte bir araștırmadır. Çalışmaya katılmayı kabul eden 317 kişi çalışma grubunu oluşturdu. KGS varlığı ve şiddetinin değerlendirilmesinde Oküler Yüzey Hastalık İndeksi ölçeği (OSDİ), sağlıkla ilişkili yaşam kalitesinin değerlendirilmesinde SF-36 yaşam kalitesi ölçeği kullanıldı. OSDİ ölçeğinden 13 ve üzeri puan alanlarda KGS olduğu kabul edildi. Çalışanların 89’u (\%28.1) erkek, 228'i (\%71.9) ise kadındır. Yaşları 22-63 arasında değişmekte olup, ortalaması 35,86 \pm 8,11 yıl idi. Araştırmamızda büro çalışanlarında KGS görülme sıklığı \%77.6 (n=246) olarak saptandı. Kadınlarda, hekim tanılı kronik hastalığı olanlarda, sürekli ilaç kullananlarda ve hekim tanılı başka bir göz hastalığı olanlarda KGS sıklığının daha yüksek olduğu saptandı. KGS olanlarda SF-36 yaşam kalitesi ölçeğinin bütün alt alanlarından alınan puan ortalamaları daha düşük idi. (Her alt alan için $\mathrm{p} \leq 0.05$ ). OSDİ ölçeğinden alınan puanlar ile SF-36 ölçeğinin tüm alt alanlarından alınan puanlar arasında negatif yönde zayıf bir korelasyon saptandı. Büro çalışanlarında KGS önemli bir sağlık sorunu olduğu ve bu sendromun saptandığı kişilerde yaşam kalitesinin daha kötü olduğu görüldü. KGS'den korunma hususunda hastalık ile ilgili farkındalık ve ekranlı araçların doğru kullanımı ile ilgili bilgilendirme etkinliklerinin düzenlenmesi, hastalığın erken teşhisi için taramaların yapılması ve saptanan olguların uzman hekimlere yönlendirilmesi önerilmektedir.
\end{abstract}

Anahtar Kelimeler: kuru göz sendromu; yaşam kalitesi; büro çalışanları; Eskişehir

Abstract: In this study, it was aimed to determine the prevalance of dry eye syndrome and evaluate the relationship with quality of life in the office workers in Eskişehir Osmangazi University Faculty of Medicine. This is a cross-sectional study conducted between January-April 2017 in Eskişehir Osmangazi University Faculty of Medicine. The study group consists of 317 office workers who are employees of Faculty of Medicine. The existence and level of dry eye syndrome was evaluated with The "Ocular Surface Disease Index" (OSDI) and SF-36 quality of life scale were used to evaluate health-related quality of life. The people who scored 13 or more in OSDI scale were accepted as having dry eye syndrome. Of the employees, $89(28.1 \%)$ were male and $228(71.9 \%)$ were female. The ages ranged from 22 to 63 years, with a mean of $35.86 \pm 8.11$ years. The prevalence of dry eye syndrome was found as $77.6 \%(\mathrm{n}=246)$. The prevalence of dry eye syndrome was found to be higher in women, in patients with clinically diagnosed chronic disease, in continuous-drug use, and in the group having another diagnosed eye disease. The mean scores of all sub-scales of SF-36 quality of life scale were lower in patients with dry eye syndrome. (For each sub-scale $p \leq 0.05$ ). There was a weak negative correlation between the scores obtained from the OSDI scale and the scores obtained from all subfields of the SF-36 scale. Dry eye syndrome is an important health problem and the quality of life was found to be worse in people with this syndrome. It is recommended office workers has to be informed about disease for the prevention and about the correct use of displays. The screening of the office workers for the early diagnosis of the disease and directing the identified cases to the specialist physicians are also important.

Keywords: dry eye syndrome; office workers; quality of life; Eskişehir

ORCID ID of the authors: E.A 0000-0002-6581-8626, G.D 0000-0002-6424-2434, S.A.Z 0000-0002-5308-9737, H.A 0000-0001-6277-7753, A.Ü 0000-0001-8353-1605, D.A 0000-0002-5263-3710

Received 30.04.2019

Accepted 24.10.2019

Online published 30.10 .2019

Correspondence: Emrah ATAY- Eskişehir Osmangazi Üniversitesi Tıp Fakültesi Halksağlığı Anabilim Dalı Eskişehir, Türkiye. e-mail: $\underline{\text { emraha06@gmail.com }}$ 


\section{Giriş}

Kuru göz sendromu (KGS), gözyaşı filminde ozmolarite artışı ve oküler yüzey inflamasyonunun eşlik ettiği, rahatsızlık hissi, görmede bozukluk ve oküler yüzeye potansiyel zarar veren gözyaşı filmi dengesizliği ile sonuçlanan gözyaşı ve oküler yüzeyin multifaktöriyel bir hastalığıdır (1).

KGS etiyolojisine göre aköz yetmezlik olan ve evaporatif KGS olarak iki sinıfa ayrılmaktadır. Aköz yetmezlik olan tipinde lakrimal bezin hasarına veya disfonksiyonuna bağlı lakrimal bezden azalmış gözyaşı üretimi sözkonusudur. Evaporatif tip ise, göz kırpma refleksinin azalması veya başka nedenlerle göz kapaklarının açık kalması, meibomian bezlerin disfonksiyonu gibi nedenlerle meydana gelen gözyaşı üretiminin normal olduğu fakat buharlaşmasının arttığı tiptir (13). KGS ile ilişkili bazı faktörler arasında kadın olma, yaşlanma, sigara içme, kafein tüketimi, kontakt lens kullanımı, allerjiler, otoimmün hastalıklar ve refraktif cerrahi geçirme yer almaktadır $(1,4-7)$.

Göz hastalıkları içerisinde sık görülen hastalıklardan olan KGS'nin sıklığı yapılan çalışmalardaki tanı kriter farklılığı ile çalışma grubundaki yaş, cinsiyet ve mesleki farkl11kklar gibi özellikler nedeniyle değişkenlik göstermektedir. Çeşitli ülkelerde yapılan çalışmalarda KGS sıklığı \% 3.9-33.7 arasında değişmektedir (5, 8-11). Türkiye'de yapılan çalışmalarda ise $\% 8.3$ ve 17.7 olarak rapor edilmiştir $(12,13)$.

KGS'nun görme fonksiyonunda önemli etkilere neden olarak; günlük yaşamdaki okuma, bilgisayarda çalı̧̧ma ve araba kullanma gibi rutin aktiviteler üzerinde olumsuz etkiye sahip olduğu, uyku kalitesini düşürdüğü, ruhsal durumu olumsuz etkilediği, yaşam kalitesini bozduğu çeşitli çalışmalarda rapor edilmiştir (14-17). KGS tanı ve tedavi için harcanan para nedeniyle direkt bir maliyete; kişilerde günlük aktivitelerde, sosyal ve fiziksel işlevlerde, iş yerinde üretkenlikte neden olduğu düşüs ile dolaylı maliyete neden olarak hastalarda önemli bir yük oluşturmaktadır $(1,18)$. Japonya'da 2014'te yapılan bir araştırmada KGS'a bağlı yıllık üretkenlik kaybının çalışan başına, toplam üretim açısından değerlendirildiğinde 6160 dolar, alınan ücret ile değerlendirildiğinde 1178 dolar olduğu bildirilmektedir (19).

Çalışmada, Eskişehir Osmangazi Üniversitesi Tıp Fakültesi hastanesi ve dekanlığında görev yapan büro çalışanlarında KGS sıklığının saptanmas1, ilişkili olduğu düşünülen bazı faktörlerin incelenmesi ve yaşam kalitesinin değerlendirilmesi amaçlandi.

\section{Gereç ve Yöntemler}

$\mathrm{Bu}$ çalışma, Ocak-Nisan 2017 yılında Eskişehir Osmangazi Üniversitesi Tıp Fakültesi Dekanlığı ve Sağlık, Uygulama ve Araştırma Hastanesi'nde görev yapan büro çalışanları arasında gerçekleştirilen kesitsel tipte bir araştırmadır.

Eskişehir Osmangazi Üniversitesi Eskişehir ilinde bulunan bir devlet üniversitesi olup; bünyesinde tıp fakültesi de dahil olmak üzere toplam 11 fakülte ve 1 Sağlık Uygulama ve Araştırma Hastanesi bulunmaktadır (20).

ESOGÜ Sağlik, Uygulama ve Araştırma Hastanesi Başhekimliği ve Tıp Fakültesi Dekanlığından 2016-2017 y1lı için bu birimlerde toplam büro çalışanı sayısının 489 olduğu bilgisine ulaşıldı. Evreni oluşturan 489 büro çalışanın tamamına ulaşılmaya çalışılmış olup örneklem seçilmemiştir. Büro çalışanları mesai saatleri içerisinde çalışma yerlerinde iki kez ziyaret edildi ve $317(\% 64.8)$ büro çalışanı çalışma grubunu oluşturdu.

Çalışmanın amacına uygun literatürden de faydalanılarak bir anket form hazırlandı (2124). Hazırlanan anket form, çalışanların bazı sosyodemografik özellikleri, KGS ile ilişkili olduğu düşünülen bazı faktörler, oküler yüzey hastalık indeksi (OSDI) ve SF-36 Yaşam Kalitesi Ölçeği ile ilgili soruları içermektedir.

Eskişehir Osmangazi Üniversitesi Rektörlüğü'nden idari izin ve Eskişehir Osmangazi Üniversitesi Girişimsel Olmayan Etik Kurul'undan etik onay alındı. Büro çalışanlarına çalışmanın amacı ve konusu 
hakkında bilgi verildi. Calıșmaya katılmayı kabul edenlerin sözlü onamları alındı. Önceden hazırlanan anket form, mesai saatleri içerisinde, çalışanların çalışma yerlerinde araştırmacılar tarafından yüz yüze görüşme yöntemi ile dolduruldu. $\mathrm{Bu}$ işlem yaklaşı olarak 15-20 dakika sürdü.

Çalıșmada KGS varlığı ve şiddetinin değerlendirilmesi için OSDI ölçeği kullanıldı. Bu ölçek, 1997 yılında Walt ve arkadaşları tarafından geliştirilmiş olup, Türkiye'de geçerlilik ve güvenilirliği 2007 yılında Özcura ve arkadaşları tarafından yapılmıştır (25). Ölçek 5'li likert tipi 12 sorudan oluşmaktadır. Ölçekten 13 ve üzeri puan alanlar KGS var olarak kabul edildi(26).

Çalışmada yaşam kalitesinin değerlendirmesinde SF-36 Yaşam kalitesi ölçeği kullanıldı. Bu ölçek, 1992 yılında ve Ware ve arkadaşları tarafından geliştirilmiş olup Türkiye'de geçerlilik ve güvenilirliği 1999 yılında Koçyiğit ve arkadaşları tarafından yapılmıştır. Ölçeğin değerlendirilmesinde son 4 hafta dikkate alınmaktadır. Toplamda 36 maddeden oluşan ölçeğin 8 alt alanı bulunmaktadır. Alt alanlardan alınan puanlar 0-100 arasinda değişmekte olup puan arttıkça yaşam kalitesi de artmaktadır $(27,28)$.

Büro çalışanlarının aile gelir durumu kendi algilarına göre "kötü, orta ve iyi" olarak değerlendirildi.

Büro çalışanlarından günde en az 1 tane düzenli olarak sigara içenler "sigara içiyor" olarak kabul edildi (29).

Elde edilen veriler, bilgisayar ortamına aktarılarak SPSS versiyon 15.0 istatistik paket programında değerlendirildi. Verilerin değerlendirilmesinde ki-kare ve student $\mathrm{t}$ testi kullandı. İstatistiksel anlamlılık değeri olarak $\mathrm{p} \leq 0.05$ olarak kabul edildi.

\section{Bulgular}

Çalışma grubunu oluşturan büro çalışanlarının 89'u (\%28.1) erkek, 228'i (\%71.9) kadın idi. Yaşları 22 ile 63 arasında değişmekte olup ortalaması $35.86 \pm 8.11$ idi. Çalışma grubunu oluşturan büro çalışanlarının 246'sında (\%77.6) KGS saptandı. Çalışma grubunda KGS olan ve olmayanların bazı sosyodemografik özelliklere göre dağılımı Tablo 1'de verildi.

Tablo 1.Çalışma grubundakilerin sosyodemografik özelliklerine göre KGS varlığı.

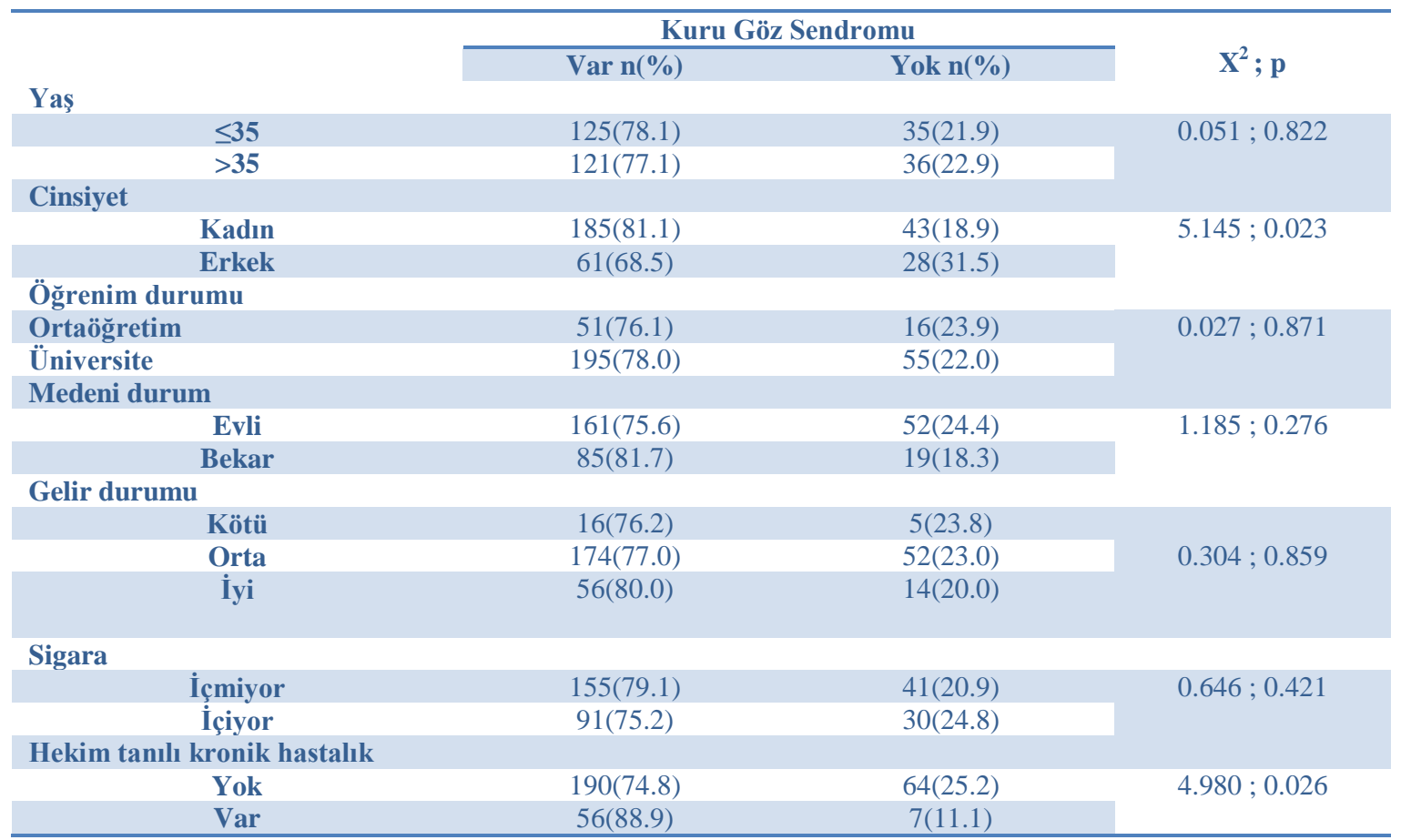




\begin{tabular}{cccc}
\hline $\begin{array}{c}\text { Sürekli ilaç kullanma durumu } \\
\text { Kullanmıyor } \\
\text { Kullanıor }\end{array}$ & $180(73.5)$ & $65(26.5)$ & $9.581 ; 0.002$ \\
\hline Hekim tanılı göz hastalığı & $66(91.7)$ & $6(8.3)$ & \\
Yok & $159(72.9)$ & $59(27.1)$ & $7.908 ; 0.005$ \\
Var & $87(87.9)$ & $12(12.1)$ & \\
\hline Göz ameliyatı geçirme öyküsü & & $6.614^{*}$ \\
\hline Yok & $235(77.6)$ & $3(22.4)$ & \\
\hline Var & $11(78.6)$ & & \\
\hline
\end{tabular}

*Fisher's exact test

Çalıșma grubunda KGS olma ve olmama durumu ile göz rengi, lens kullanımı, ișyeri dışında bilgisayar kullanımı, günlük bilgisayar kullanım süresi, ekran filtresi kullanımı, televizyon izleme, cep telefonu kullanımı ve kitap-dergi okuma ile ilișki saptanmadi $(\mathrm{p}>0.05)$.
Büro çalışanlarının OSDİ'den aldıkları puanlar 0.00 ile 93.75 arasında değişmekte olup ortalaması, $32.39 \pm 21.69$ idi. Çalışma grubunda KGS olan ve olmayanların SF-36 alt alanlarından aldıkları puanların dağılımı Tablo 2'de verilmiştir.

Tablo 2. KGS olan ve olmayanların SF-36 alt alanlarından aldıkları puanların dağılımı

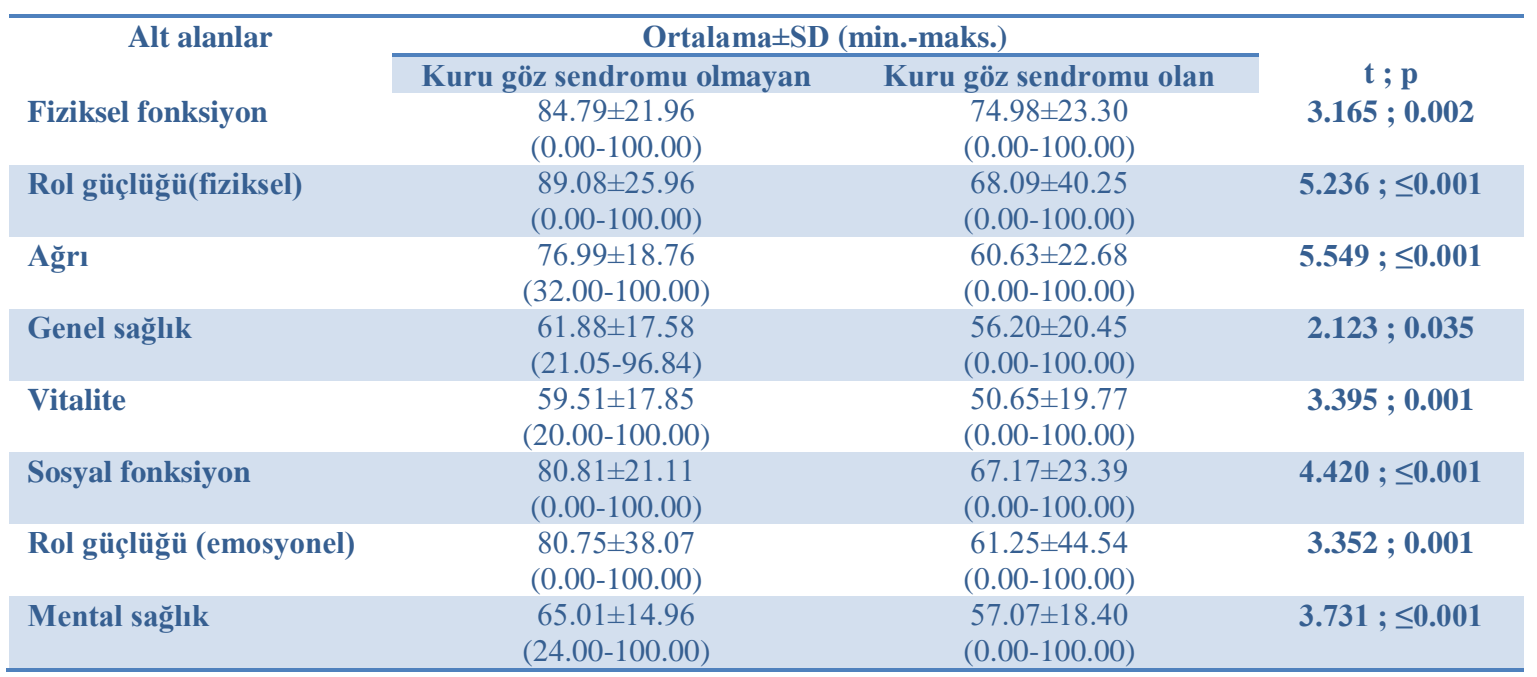

\section{Tartışma ve Sonuç}

KGS oldukça s1k görülen bir göz hastalı̆̆ olması nedeniyle son yıllarda önemli bir halk sağlığı problemi haline gelmiștir (30). Değișik popülasyonlarda görülme siklığının \%5.5-59.0 arasında değiştiği bildirilmektedir (31-33). Göz kliniğine başvuran hastaların da büyük bir kısminda KGS saptandığ 1 rapor edilmektedir (34). Calışmada büro çalışanlarının \%77.6 'sında KGS olduğu görüldü. Yapılan çalışmalarda farklı KGS tanı ölçütlerinin kullanılması çalışmalarda bildirilen farklı sonuçların nedenlerden birisi olabilir (35). Araştırmada sıklığın yüksek çıkmasının nedeni çalışma grubunu meslekleri gereği uzun süre ekrana bakan ve bu açıdan riskli grup haline gelen büro çalışanlarının oluşturması olabilir.

Yaşın ilerlemesi ile birlikte gözyaş1 üretiminden sorumlu Meibomian ve lakrimal 
bezlerde hücre dejenerasyonu gelişerek gözyaşı üretimi azalır ve içeriğindeki lipid/su oranın düşmesi ile buharlaşma miktarı arttığından KGS siklığının artması beklenir $(13,35)$. Yapılan bir çalışmada ileri yaşın KGS riskini yaklaşık 2 kat arttırdığ bildirilmektedir (21). Çalışma grubunda yaş grupları arasında KGS sıklı̆̆ 1 açısından bir fark bulunamadı. Yapılan çeşitli çalışmalarda da benzer sonuç bildirilmektedir $(34,36,37)$. Schaumberg ve arkadaşlarının yaptıkları bir araştırmada ise yaş arttıkça KGS sıklığının arttığ1 rapor edilmektedir (38). Araştırma grubunun daha genç yașta, çalıșan bireylerden oluşmas1, yaş ile kuru göz sendromu arasındaki ilişkinin saptanamamasının nedenleri arasında sayılabilir.

Kadınlarda testosteron eksikliği ve östrojen/progesteron fazlalığı nedeniyle lakrimal ve Meibomian bez disfonksiyonu, lipid yapımı azalması ve buharlaşmaya bağlı olarak KGS'nin daha sık görülmesi beklenen bir durumdur $(3,38,39)$. Bu çalışmada erkeklere göre kadınlar arasında KGS sıklığının daha yüksek olduğu saptanmıştır. Çeşitli ülkelerde yapılan bazı çalışmalarda da benzer sonuç rapor edilmiştir $(8,40,41)$ Lee ve arkadaşlarının yaptıkları bir çalışmada ise erkeklerde KGS sıklığının kadınlara göre daha yüksek olduğu bildirilmiştir (42).

Romatolojik hastalıklar (Sjögren Sendromu, Romatoid Artrit vb.), Diabetes Mellitus ve tiroid hastalıkları gibi kronik hastalıklardaki inflamatuar süreçler, lakrimal bez disfonksiyonu, bazal gözyaşı salınımında azalma KGS'nin daha sık görülmesine neden olmaktadır (13, 43). Çalışmamızda KGS s1klığının hekim tanılı kronik hastalığı olan kişilerde olmayanlara göre daha yüksek olduğu saptandı. Ceșitli çalıșmalarda KGS'nin kronik hastalığı olan kişilerde daha sık olduğu raporlanmıştır $(22,44)$. Ancak, Uchino ve arkadaşlarının yaptıkları araştırmada ise KGS ve kronik hastalıklar arasında bir ilişki saptanamadığı bildirilmiştir (19).

Göz hastalıklarının, kronik inflamasyona yol açarak sitokinler aracılığıyla oküler yüzeyin koruyucu tabakasinda hasara ve KGS'ye neden olmas1 beklenmektedir (40).
Çalışmamızda hekim tanılı göz hastalığına sahip olanlarda KGS sıklığının daha yüksek olduğu bulundu. Yapılan bazı çalışmalarda da çalışmamızla benzer yönde sonuç raporlanmıştır $(45,46)$.

KGS'ye bağlı olarak gözlerde meydana gelen ağrı, görme fonksiyonlarında bozukluklar kişinin günlük aktivitelerinin sınırlanmasına (merdiven inip çıkma, yer değiştirme), yürüttükleri işin niteliği ile alakalı olarak işgücü kaybına ve kişinin başta kitap/dergi okuma, televizyon izleme, hobi gibi aktiviteleri yerine getirememelerine bağl1 zamanla ortaya çıkan psikolojik bir takım olumsuzluklara yol açabilir. Tüm bunlar tıbbi, ekonomik ve sosyal alanlarda kişinin yaşam kalitesinin bozulmasına neden olacaktır (4750).

Çalışmamızda KGS ve yaşam kalitesi değerlendirildiğinde KGS olanlarda SF-36 ölçeğinin tüm alt alanlarında yaşam kalitesinin daha kötü olduğu saptand1. Schaumberg ve arkadaşları ile Miljanovic ve arkadaşlarının ABD'de yaptıkları çalışmalarda KGS olanların yaşam kalitesinin daha kötü olduğu ve günlük aktivitelerinde önemli ölçüde kisitlılık olduğu bildirilmektedir $(8,30)$.

\section{Sonuç ve Öneriler}

Gözyaş1 ve oküler yüzeyin mutlifaktöriyel bir hastalığ1 olan KGS, hem hastalığın yarattığ1 olumsuzluklar ve dolaylı fonsiyonel kayıplar hem de yaşam kalitesine etkileri sebebiyle üzerinde önemle durulması gereken çok boyutlu bir rahatsızlıktır. KGS'de hastalığ önlemenin yanı sıra gelişmekte olan bir süreci erken tanı ile tespit etmek de mümkündür.

Kişilerin çalışırken gerekli önlemleri almalarını sağlamak ve semptomları olanların bunları önemseyerek konunun mutlak hakimi olan bir göz hastalıkları uzmanına muayene olmaya sevketmek adına bireylere konuyla ilgili eğitim verilmesi faydalı olacaktır. Doğru bilgi ile farkındalık sağlanması hastalığın doğrudan ya da dolaylı etkilerinden korunma ve yaşam kalitesinin düşmemesi açısından önemlidir. 


\section{KAYNAKLAR}

1. Foulks G, Lemp M, Jester J, Sutphin J, Murube J, Novack GJOS. report of the international dry eye workshop (DEWS). 2007;5:65-204.

2. Ding J, Sullivan DA. Aging and dry eye disease. Exp Gerontol. 2012;47:483-90.

3. Utine CA. Kuru Göz Oluşum Mekanizması ve Sinıflandirılması. MN Oftalmoloji 2016;23:1-8

4. Viso E, Rodriguez-Ares MT, Gude F. Prevalence of and associated factors for dry eye in a Spanish adult population (the Salnes Eye Study). Ophthalmic Epidemiol. 2009;16:15-21.

5. Moss SE, Klein R, Klein BE. Prevalence of and risk factors for dry eye syndrome. Arch Ophthalmol. 2000;118:1264-8.

6. Paulsen AJ, Cruickshanks KJ, Fischer ME, et al. Dry eye in the beaver dam offspring study: prevalence, risk factors, and health-related quality of life. Am J Ophthalmol. 2014;157:799-806.

7. Ang RT, Dartt DA, Tsubota K. Dry eye after refractive surgery. Curr Opin Ophthalmol. 2001;12:318-22

8. Schaumberg DA, Dana R, Buring JE, Sullivan DA. Prevalence of dry eye disease among US men: estimates from the Physicians' Health Studies. Arch Ophthalmol. 2009;127:763-8.

9. Schaumberg DA, Sullivan DA, Buring JE, Dana MR. Prevalence of dry eye syndrome among US women. Am J Ophthalmol. 2003;136:318-26.

10. Farrand KF, Fridman M, Stillman IO, Schaumberg DA. Prevalence of Diagnosed Dry Eye Disease in the United States Among Adults Aged 18 Years and Older. Am J Ophthalmol. 2017;182:90-8.

11. Lin P-Y, Tsai S-Y, Cheng C-Y, Liu J-H, Chou P, Hsu W-M. Prevalence of dry eye among an elderly Chinese population in Taiwan: the Shihpai Eye Study. Ophthalmology. 2003;110:1096-101

12. Yilmaz U, Gokler ME, Unsal A. Dry eye disease and depression-anxiety-stress: A hospital-based case control study in Turkey. Pak J Med Sci. 2015;31:626-31.

13. Kıră̆ N, Temel AB. Yaşlı Bireylerde Kuru Göz Semptomu Sıklığı ve İlişkili Faktörler. Anadolu Hemşirelik ve Sağllk Bilimleri Dergisi. 2016;19:243-51

14. Miljanović B, Dana R, Sullivan DA, Schaumberg DA. Impact of dry eye syndrome on vision-related quality of life. Am J Ophthalmol. 2007;143:40915.

15. Kawashima M, Uchino M, Yokoi N, Uchino Y, Dogru M, Komuro A, et al. The association of sleep quality with dry eye disease: the Osaka study. Clinical ophthalmology (Auckland, NZ). 2016;10:1015

16. Tounaka K, Yuki K, Kouyama K, Abe T, Tsubota $\mathrm{K}$, Kawabe $\mathrm{H}$, et al. Dry Eye Disease Is Associated with Deterioration of Mental Health in Male Japanese University Staff. Tohoku J Exp Med. 2014;233:215-20.

17. Salib GM, McDonald MB, Smolek M. Safety and efficacy of cyclosporine $0.05 \%$ drops versus unpreserved artificial tears in dry-eye patients having laser in situ keratomileusis. J Cataract Refr Surg. 2006;32:772-8.

18. Gayton JL. Etiology, prevalence, and treatment of dry eye disease. Clinical ophthalmology (Auckland, NZ). 2009;3:405.

19. Uchino M, Uchino Y, Dogru M, Kawashima M, Yokoi N, Komuro A, et al. Dry eye disease and work productivity loss in visual display users: the Osaka study. Am J Ophthalmol. 2014;157:294300.

20. Eskişehir Osmangazi Üniversitesi. Fakülteler, 2018 Available from: https://ogu.edu.tr/Icerik/Index/24/fakulteler. Erişim Tarihi: [20.11.2018].

21. Bakkar MM, Shihadeh WA, Haddad MF, Khader YS. Epidemiology of symptoms of dry eye disease (DED) in Jordan: A cross-sectional non-clinical population-based study. Contact Lens and Anterior Eye. 2016;39:197-202.

22. Paulsen AJ, Cruickshanks KJ, Fischer ME, Huang G-H, Klein BE, Klein R, et al. Dry eye in the beaver dam offspring study: prevalence, risk factors, and health-related quality of life. Am J Ophthalmol. 2014;157:799-806.

23. Barabino S, Labetoulle M, Rolando M, Messmer EM. Understanding symptoms and quality of life in patients with dry eye syndrome. The ocular surface. 2016;14:365-76.

24. Galor A, Feuer W, Lee DJ, Florez H, Carter D, Pouyeh B, et al. Prevalence and risk factors of dry eye syndrome in a United States veterans affairs population. Am J Ophthalmol. 2011;152:377-84.

25. Özcura F, Aydin S, Helvaci MR. Ocular surface disease index for the diagnosis of dry eye syndrome. Ocul Immunol Inflamm. 2007;15(5):389-93.

26. Huang J-F, Zhang Y, Rittenhouse KD, Pickering EH, McDowell MT. Evaluations of tear protein markers in dry eye disease: repeatability of measurement and correlation with disease. Invest Ophthalmol Vis Sci. 2012;53:4556-64.

27. Ware Jr JE, Sherbourne CD. The MOS 36-item short-form health survey (SF-36): I. Conceptual framework and item selection. Medical care. 1992:473-83

28. Koçyigit H. Kısa Form-36 (KF-36)'nm Türkçe versiyonunun güvenilirligi ve geçerliliği. İlaç ve tedavi dergisi. 1999;12:102-6.

29. Tolonen H, Wolf H, Jakovljevic D, Kuulasmaa K. Review of surveys for risk factors of major chronic diseases and comparability of the results. EHRM Project Oslo. 2002.

30. Miljanović B, Dana R, Sullivan DA, Schaumberg DA. Impact of dry eye syndrome on vision-related quality of life. Am J Ophthalmol. 2007;143:40915.

31. McCarty CA, Bansal AK, Livingston PM, Stanislavsky YL, Taylor HR. The epidemiology of dry eye in Melbourne, Australia. Ophthalmology. 1998;105:1114-9.

32. Lin P-Y, Tsai S-Y, Cheng C-Y, Liu J-H, Chou P, Hsu W-M. Prevalence of dry eye among an elderly 
Chinese population in Taiwan: the Shihpai Eye Study. Ophthalmology. 2003;110:1096-101.

33. Moss SE, Klein R, Klein BE. Prevalence of and risk factors for dry eye syndrome. Archives of ophthalmology. 2000;118:1264-8.

34. Yilmaz U, Gokler ME, Unsal A. Dry eye disease and depression-anxiety-stress: A hospital-based case control study in Turkey. Pak J Med Sci. 2015;31:626-31.

35. Janine A. The epidemiology of dry eye disease: report of the epidemiological subcommittee of the international dry eye workshop. Ocul Surf. 2007;5:93-107.

36. Kawashima M, Uchino M, Yokoi N, Uchino Y, Dogru M, Komuro A, et al. The association of sleep quality with dry eye disease: the Osaka study. Clinical ophthalmology (Auckland, NZ). 2016;10:1015.

37. Portello JK, Rosenfield M, Bababekova Y, Estrada JM, Leon A. Computer-related visual symptoms in office workers. Ophthalmic Physiol Opt. 2012;32:375-82.

38. Schaumberg DA, Sullivan DA, Buring JE, Dana MR. Prevalence of dry eye syndrome among US women. Am J Ophthalmol. 2003;136:318-26.

39. Aydın Akova Y. ve Açıkalın B. Kadınlarda Kuru Göz. MN Oftalmoloji 2016;23:60-3

40. Bingöl N. Kuru Göz Tanılı Hastaların Epidemiyolojik Araştırılması. Uzmanlık Tezi. İstanbul: Okmeydanı Eğitim ve Araştırma Hastanesi; 2009.

41. Uchino M, Schaumberg DA, Dogru M, Uchino Y, Fukagawa K, Shimmura S, et al. Prevalence of dry eye disease among Japanese visual display terminal users. Ophthalmology. 2008;115:1982-8.

42. Lee A, Lee J, Saw S, Gazzard G, Koh D, Widjaja $\mathrm{D}$, et al. Prevalence and risk factors associated with dry eye symptoms: a population based study in Indonesia. British Journal of Ophthalmology. 2002;86:1347-51.

43. Dursun Altınörs D. ve Asena L. Sistemik Hastalıklar ve Kuru Göz. MN Oftalmoloji 2016;23:53-59.

44. Nowak M, Marek B, Kos-Kudła B, Kajdaniuk D, Siemińska L. Tear film profile in patients with active thyroid orbithopathy. Klinika oczna. 2005; 107:479-82.

45. Bayer A. ve Özge G. Glokom, Glokom İlaçları ve Kuru Göz. MN Oftalmoloji 2016;23:91-5.

46. Fujishima H, Toda I, Shimazaki J, Tsubota K. Allergic conjunctivitis and dry eye. $\mathrm{Br} \quad J$ Ophthalmol. 1996;80:994-7.

47. Knudtson MD, Klein BE, Klein R, Cruickshanks KJ, Lee KE. Age-related eye disease, quality of life, and functional activity. Archives of Ophthalmology. 2005;123:807-14.

48. Schiffman RM, Walt JG, Jacobsen G, Doyle JJ, Lebovics G, Sumner W. Utility assessment among patients with dry eye disease. Ophthalmology. 2003;110:1412-9.

49. Buchholz P, Steeds CS, Stern LS, Wiederkehr DP, Doyle JJ, Katz LM, et al. Utility assessment to measure the impact of dry eye disease. The ocular surface. 2006;4:155-61.

50. Brown MM, Brown GC. Utility assessment and dry eye disease. Ophthalmology. 2004;4:852-3. 